\title{
Bacterial-Induced Blood Pressure Reduction: Mechanisms for the Treatment of Hypertension via the Gut
}

\section{OPEN ACCESS}

Edited by:

Guido laccarino,

University of Naples Federico II, Italy

Reviewed by:

Grazia Tamma,

University of Bari Aldo Moro, Italy

Piyali Chatterjee,

Central Texas Veterans Health Care System, United States

*Correspondence:

Tyler Alexander Cookson

tcookson@ualberta.ca

Specialty section:

This article was submitted to

Hypertension,

a section of the journa

Frontiers in Cardiovascular Medicine

Received: 07 June 2021

Accepted: 16 July 2021

Published: 13 August 2021

Citation:

Cookson TA (2021) Bacterial-Induced

Blood Pressure Reduction:

Mechanisms for the Treatment of

Hypertension via the Gut.

Front. Cardiovasc. Med. 8:721393.

doi: 10.3389/fCvm.2021.721393
Tyler Alexander Cookson*

Department of Physiology, University of Alberta, Edmonton, AB, Canada

Hypertension is a major risk factor for the development of cardiovascular disease. As more research into the gut microbiome emerges, we are finding increasing evidence to support that these microbes may have significant positive and negative effects on blood pressure and associated disorders. The bacterial-derived metabolites that are produced in the gut are capable of widespread effects to several tissue types and organs in the body. It is clear that the extensive metabolic function that is lost with gut dysbiosis is unlikely to be replenished with a single metabolite or bacterial strain. Instead, combinations of bacteria and concomitant therapies will provide a more well-rounded solution to manage hypertension. The bioactive molecules that are recognized in this review will inform on ideal characteristics of candidate bacteria and provide direction for future research on the gut microbiome in hypertension.

Keywords: hypertension, gut microbiome, butyrate, probiotics, inflammation, cardiovascular disease, dysbiosis

\section{INTRODUCTION}

Hypertension is a significant risk factor for development of cardiovascular disease-the leading cause of death worldwide (1). It is believed that the gut microbiome may be involved in the development and the perpetuation of the hypertensive phenotype. The use of live bacteria has the potential to confer a wider array of functionality compared to supplementation of a few metabolites, such as short-chain fatty acids (SCFAs). Additionally, due to the widespread changes observed in the abundance of gut microbes during hypertension (2-6), it is unlikely that supplementation of a single bacterial strain will completely normalize blood pressure in a hypertensive patient. Using a combination of species and strains as probiotics has the potential to temporarily restore metabolic function that is lost in hypertensive microbial dysbiosis. The gut microbiome is complex and a group of strains may provide additional functionality through cooperation, such as crossfeeding, and reintroduce a multi-faceted solution in which many components work in concert to treat hypertension in a way that could not be achieved by supplementing a single metabolite or bacterial strain.

Notably, as germ-free animals exhibit marked reductions in blood pressure (7), there are likely species of gut bacteria that promote the development of hypertension. Therefore, identifying properties of bacteria that can facilitate reductions in blood pressure is important for future research. This review will discuss the potential involvement of various gut metabolites and processes in the development and perpetuation of hypertension and propose a comprehensive mechanism for a bacterial-induced blood pressure reduction to serve as a guide for properties of bacteria to investigate further. 


\section{DIETARY BIOACTIVE MOLECULES SYNTHESIZED AND METABOLIZED BY GUT MICROBES WITH EFFECTS ON BLOOD PRESSURE}

\section{Butyrate, Acetate, Lactate, and Isovalerate}

Along with acetate and propionate, butyrate is one of the main SCFAs produced by gut microbes in the gut. Currently, butyrate is being studied primarily for its anti-inflammatory properties $(8,9)$ and intestinal barrier activity through tight junction expression $(10,11)$. However, newer research questions the efficacy of butyrate in human tissue (12). There is early evidence to support that butyrate promotes reductions in blood pressure, but additional research is required to determine the validity of these results in human models.

In hypertensive patients, researchers have observed depleted circulating butyrate (13). When butyrate is infused intracolonically in rats, there was a more profound hypotensive effect compared to when butyrate was infused intravenously (14). Additionally, the intracolonic butyrate reduced heart rate (HR) in these rats, while the intravenous butyrate did not, suggesting that butyrate can stimulate a central hypotensive effect via pathways in the gut. Interestingly, butyrate activates Gpr41/43 and OR51E1 receptors on enterochromaffin cells (ECCs) to release serotonin (5-HT) (15-17), which binds to $5-\mathrm{HT}_{3}$ receptors on vagal afferents (18). As activation of vagal afferents can stimulate glutamate release at the nucleus tractus solitarius (NTS) of the brain $(19,20)$, it is possible that the glutamate in the NTS can elicit a central hypotensive effect (19). While this pathway is only a hypothesis, it may help to explain the hypotensive effects observed by intracolonic butyrate that is not seen with intravenous infusion and should be investigated further. Importantly, chronic stimulation of ECCs by butyrate increases 5-HT synthesis (15), but acute exposure does not (21), indicating a need for consistent supplementation either directly or via production by probiotics. This pathway may explain the profound hypotensive effect and the reduction in HR that is observed with intracolonic butyrate, but not intravenous butyrate. Although 5-HT may have a role in the central hypotensive effects mediated by the gut-brain axis as described above, high circulating levels of 5-HT can also constrict blood vessels and contribute to hypertension $(22,23)$.

It should be noted that intravenous butyrate does still have a hypotensive effect. Additional research has shown that butyrate can inhibit sympathetic tone in peripheral blood vessels, including the mesenteric arteries and the gracilis muscle arteries, via the Gpr41/43 receptors (14) and reduce norepinephrine (NE) production by destabilizing tyrosine hydroxylase mRNA stability (24) to attenuate vasoconstriction. Butyrate also dilates blood vessels independent of the Gpr41/43 receptors (25), potentially through the OR51E1 receptors present in vascular smooth muscle and renal vasculature $(26,27)$. Moreover, butyrate suppresses angiotensin II (AngII)-induced hypertension by inhibiting renal prorenin receptors and the intrarenal renin-angiotensin system (RAS) (28). In the brain, intracerebroventricular injection of butyrate can also centrally reduce blood pressure directly by altering neuronal activity in cardio-regulatory regions of the brain (29).

Some researchers suggest that in a subset of hypertensive patients, butyrate uptake is impaired in the proximal colon, such as that which is observed in spontaneously hypertensive rats (SHRs) $(29,30)$. This theoretically results in an increase in intracolonic butyrate, and therefore an increase in 5-HT release from ECCs. Under normal conditions, this would be expected to reduce sympathetic output centrally, however, it is possible that the hypotensive effect is dampened due to reduced sensing mechanisms such as lower proportions of appropriate receptors in the brain. For example, SHRs have reduced "SCFA-sensing receptors" in the brain that would normally aid in producing a hypotensive effect (29). Interestingly, fecal transplant from a normotensive rat into an SHR not only normalized blood pressure, but also increased Gpr41 and Gpr43 receptors in the brain (31). Therefore, supplementation of certain bacteria or combinations of bacteria may not only have mechanisms to reduce blood pressure metabolically, but also re-sensitize the body to hypotensive signals by altering receptor expression. Bacteria from the Faecalibacterium, Clostridium, Eubacterium, and Roseburia genera are major butyrate producers, but many species of bacteria are capable of butyrate production $(32,33)$.

The primary use for acetate and lactate in this proposed pathway is for the production of butyrate. For example, species of Clostridium can utilize acetate and lactate to produce butyrate (34). However, acetate is known to activate a parasympathetic response (35), although the exact means by which this is accomplished has yet to be elucidated. Acetate is known to bind to Gpr41 and Gpr43 (36), and may act through the ECCs in a similar fashion to butyrate. Importantly, acetate can reduce blood pressure (37), but whether this is via its own actions, through butyrate production, or a combination is also not known. In addition to promoting butyrate production, acetate can downregulate the metabolism of butyrate in the kidney to maintain its availability and prolong its actions (37). Much less is known about the branched short-chain fatty acid (BSCFA) isovalerate. From what is known, isovalerate can activate OR51E1 on ECCs, which is similar to butyrate and may contribute to a centrally induced hypotensive response (16). Additional actions of isovalerate in the context of blood pressure needs to be explored further to determine the magnitude of its effects, if there are any at all.

\section{Propionate}

In addition to butyrate, propionate is another major SCFA produced in the gut and is therefore a metabolite of high interest regarding its effects in the body, especially in disease states. Recently, a study evaluating the effects of propionate on hypertensive cardiac damage and atherosclerosis found that propionate decreased blood pressure, reduced systemic inflammation, improved vascular dysfunction, and attenuated atherosclerosis in mice via reductions in $\mathrm{T}_{\mathrm{H}} 17$ cells (38). This study suggests that the effects of propionate on blood pressure and cardiovascular damage are largely T-cell dependent, but have yet to be described in great detail. However, it is known 
that propionate can have a direct effect on blood pressure that also happens to be dose-dependent. Lower concentrations of propionate will activate Gpr41 and decrease blood pressure, while higher concentrations will activate Olfr78 (with OR51E2 being the human homolog) to increase blood pressure via renin signaling in the renal juxtaglomerular apparatus $(39,40)$. In addition to Gpr41, propionate can also activate Gpr43 similarly to butyrate (36) and therefore might also stimulate 5-HT release from ECCs. While this has not been investigated explicitly, a Gpr43 knockout model with supplementation of propionate will clarify the extent to which propionate affects blood pressure through the Gpr43 receptor.

Concerning the production of propionate by gut bacteria, certain strains of Enterococci can utilize lipids, such as cholesterol, to produce propionate which can reduce the development of atherosclerosis (41). Importantly, the growth of Enterococci is inhibited by propionate (42), potentially as a feedback mechanism to limit propionate production by the Enterococci that may prevent an excess of propionate from increasing blood pressure. It should be noted that butyrate, succinate, and lactate can be converted to propionate (43), so increased levels of propionate may occur through butyrate, succinate, or lactate conversion rather than direct synthesis.

\section{Gamma-Aminobutyric Acid}

Similar to butyrate, circulating Gamma-Aminobutyric Acid (GABA) is also reduced in hypertensive patients (30). Luminal GABA in the gut binds to $\mathrm{GABA}_{\mathrm{B}}$ receptors on ECCs, stimulates 5 -HT release, attenuates the sympathetic response, and has a hypotensive effect (44). In addition, it should be noted that germfree mice, which demonstrate reduced blood pressure (7), also have depleted GABA in the stool and the blood (45) suggesting that changes in circulating and gut luminal GABA is not wholly responsible for the observed changes in blood pressure, if at all. Activation of $\mathrm{GABA}_{\mathrm{B}}$ receptors on vagal afferents has been described to inhibit afferent signaling (46). It would be expected from this that higher concentrations of intra-luminal GABA would increase transport of GABA across the intestinal barrier and blunt vagal afferent activity; however, there is a strong inverse relationship between intraluminal GABA and blood pressure (44) that suggests the hypotensive effects of GABA outweigh the inhibitory activity on the vagal afferents. The effects of GABAergic signaling in the gut are still controversial and should be explored further; however, additional beneficial roles such as reducing inflammation (47) have been described for GABA in the gut.

\section{Lipopolysaccharide and Gut Inflammation}

Intestinal inflammation is suggested to play a large in part in the development of hypertension and cardiovascular disorders as endothelial dysfunction is observed in arteries located far from the inflamed intestines, such as in inflammatory bowel diseases (48). Moreover, intestinal inflammation promotes microbial dysbiosis and the breakdown of commensal bacteria (49) that are required for normal vascular physiology (50). High levels of Lipopolysaccharide (LPS), a major component of the outer membrane of Gram-negative bacteria, in the intestinal lumen degrades tight junction proteins and compromises gut barrier integrity $(51,52)$ which can potentially be rescued by butyrate (53). A consequence of reduced gut barrier function is "leaky gut," in which the permeability between the gut lumen and the circulation is not as closely controlled. Bacterial translocation into the circulation can cause a sterile systemic inflammation as bacteria are degraded by host immune cells and release LPS (54-56). A murine model showed that injection of LPS into the periphery or directly into the brain induced neuroinflammation either by crossing the blood-brain barrier or by stimulating afferent nerves at circumventricular organs to alter blood-brain barrier permeability (57). Though still being investigated, neuroinflammation contributes to central sympathetic hyperactivity $(58,59)$ to promote increases in blood pressure, including neuroinflammation induced by LPS (60).

\section{Histamine}

Histamine has strong hypotensive effects (61). By increasing the permeability of capillaries (62), histamine increases fluid extravasation, reduces blood volume, and therefore reduces blood pressure. In addition, histamine is a strong vasodilator, which contributes to the observed hypotensive effects. Of interest, histamine can suppress inflammasome signaling to attenuate gut inflammation by LPS, limit IL-18 secretion, and reduce the expression of antimicrobial peptides that promote inflammation (63) to maintain gut barrier integrity. In the heart, histamine can impair the actions of AngII by reducing $\mathrm{AT}_{1}$ receptor expression in the heart via $\mathrm{H}_{3}$ receptors (64).

\section{Bile Acids and Trimethylamine- $\mathbf{N}$-oxide}

Although a majority (95\%) of bile acids are reabsorbed and recycled, gut bacteria are able to manipulate them while they are present in the gut lumen. Certain species of bacteria can convert primary bile acids to secondary bile acids, such as deoxycholic acid and lithocholic acid, which bind to TGR5 receptors on ECCs to stimulate 5-HT synthesis and release $(65,66)$. Trimethylamine- $N$-oxide (TMAO) is currently a highly researched metabolite in the area of hypertension. Several bacteria can promote TMAO synthesis via the production of trimethylamine (TMA) from phosphatidylcholine, choline, and carnitine metabolism. Unfortunately, TMAO reduces primary bile acid synthesis in the liver (67), which results in less activation of TGR5 receptors on ECCs. TMAO also contributes to hyperlipidemia by blocking reverse cholesterol transport and increasing forward cholesterol transport (67). In the vasculature, TMAO increases endothelial inflammation and inhibits endothelial nitric oxide (NO), suppressing vasodilation $(68,69)$.

TMAO-rich foods are also an important component of the Mediterranean diet and while TMAO is largely being investigated for its pathogenic roles, it may also have several beneficial biological functions. In the gut, TMAO serves as an electron acceptor in oxidative phosphorylation for anaerobic bacteria to reduce the production of reactive oxygen species (70) while also inhibiting the growth of pathogenic bacteria (71) suggesting that TMAO has protective functions for both bacteria and the host. In rodent models, TMAO prolonged the hypertensive effects of AngII; however, when TMAO was infused on its own, there were no noticeable negative effects (72). In fact, oral L-carnitine, which 
is ultimately converted into TMAO, elicits reduced markers of vascular injury (73). Thus, as TMAO on its own exhibits several positive effects and lacks strong deleterious effects in the absence of other well-known contributors to hypertension, it is unlikely to induce hypertension alone but may cooperate with other pro-hypertensive molecules, such as AngII.

\section{Hyperlipidemia}

Elevated serum lipids or hyperlipidemia can contribute to increased blood pressure through various means, including atherosclerosis. Atherosclerosis is the buildup of plaque in the walls of blood vessels, which narrows the lumen of the blood vessel and increases blood pressure. Serum lipids can also increase oxidative stress in the vascular endothelia, thus increasing monocyte recruitment, and reducing $\mathrm{NO}$ availability $(74,75)$. As NO is a strong vasodilator, this impairs vasodilation and can further increase blood pressure. Bacteria that promote the production of secondary bile acid synthesis may induce more cholesterol use for the de novo synthesis of bile, resulting in less serum lipids.

In germ-free mice, there are no differences in endothelialdependent or independent relaxation compared to conventional mice (50). This suggests that the gut microbes in conventional animals do not alter endothelial function in the absence of a prohypertensive challenge. Additionally, a lack of microbes alone cannot explain the differences in endothelial-dependent relaxation. Instead, the presence of pathogenic bacteria or a dysbiotic gut microbiome profile with unfavorable net effects on vascular endothelial function may be able to explain these differences.

\section{Arachidonic Acid}

Many actions for arachidonic acid (AA) have been described, but many are contradictory or often dose dependent. For example, several sex differences in the actions of AA have been distinguished. Firstly, AA exacerbates inflammation in male mice, but attenuates it in females (76). Zhuang et al. (76) attributed this observation to the fact that the AA promoted the survival of butyrate-producing bacteria and upregulated Gpr41 expression in the females. Male mice also showed reduced circulating 5-HT compared to the females in response to AA, likely due to reduced butyrate activating Gpr41 on ECCs. Evidently, sex differences in the effects of many molecules exist, including in NO-dependent vascular relaxation (50), and should researched in more detail. These findings are important and could possibly describe differences that lead to sex-dependent treatments of hypertension.

In rats, gut microbiota-derived AA reduces corticosterone, the rodent equivalent of cortisol (77). This stress hormone is heavily involved in the pathophysiology of hypertension as it can be converted into aldosterone that increases salt and water retention to increase blood volume and therefore blood pressure. Unfortunately, AA is also linked to inflammation (78). Typically, AA will stimulate an inflammatory reaction, while the $n-3$ fatty acids will counteract these effects with antiinflammatory actions. However, appropriate levels of AA appear to be beneficial, especially in certain populations. Although there is some potential for increased inflammation with arachidonic acid, the anti-inflammatory effects of other metabolites, such as the SCFAs, should strongly oppose any inflammatory response.

\section{Indoles}

Indoles are aromatic, heterocyclic, organic compounds that are found in the gut. As a metabolite of tryptophan, the functions of indole in health and disease are becoming more widely researched. A recent study by Huć et al. (79) investigated the peripheral and central hemodynamic mechanisms of indole. When they infused indole intravenously in male rats, there was an observed dose-dependent increase in blood pressure, but no noticeable change in heart rate. However, this same study shows that intracerebroventricular infusion of indole reduces both blood pressure and heart rate. Even more interestingly, these changes were negated by pre-treatment with 5 -HT receptor blockers (79). Therefore, indoles function in both the periphery and centrally via serotonergic mechanisms to alter blood pressure. While peripherally indoles are prohypertensive, indoles in the brain appear to be anti-hypertensive.

\section{Glucagon-Like Peptide 1}

SCFAs have been shown to promote Glucagon-Like Peptide 1 (GLP-1) release in the gut. For example, propionate stimulates GLP-1 secretion from L-cells via Gpr43 (80). Moreover, butyrate and acetate stimulate secretion of GLP-1 from enteroendocrine L-cells independent of Gpr41 and Gpr43 (81). A meta-analysis found that GLP-1 and GLP-1 receptor agonists were able slightly reduce blood pressure, but GLP-1 levels were not significantly associated with hypertension (82). Additionally, although the net effect is quite minor, GLP-1 may have a dose-dependent relationship with blood pressure in which high doses can exhibit a hypotensive effect (83).

\section{METABOLITES CONTRIBUTING TO HYPERTENSION VIA THE GUT-KIDNEY AXIS}

The kidney is the final common pathway for the development of hypertension. This statement is supported by early transplantation studies in rats. In fact, transplantation of a hypertensive kidney into a normotensive animal is sufficient to increase blood pressure, and conversely, transplantation of a normotensive kidney into a hypertensive animal can normalize blood pressure $(84,85)$. Additionally, germ-free studies have shown that mice lacking a gut microbiome develop much more severe kidney disease (86). As such, the gut microbiome and gut-derived metabolites that directly impact kidney function and contribute to chronic kidney disease are important in the context of blood pressure regulation.

\section{Oxalate}

There may be a link between butyrate, oxalate, and hypertension, although this area of research could be expanded upon. As less butyrate is produced in hypertension as described above, there is weakened intestinal barrier function as butyrate induces expression of tight junctions between the gut epithelia (11). With the development of a "leakier" gut, more oxalate will be absorbed into the circulation. Once in the kidney, oxalate 
promotes the formation of kidney stones and can damage the kidney (87), potentially impairing the long-term control of blood pressure. Additionally, kidney stone formation is associated with higher risk of developing hypertension (88). There has been a focus on the use of $O$. formigenes in preventing kidney stones as it has demonstrated the ability to directly metabolize oxalate, utilizing acetate in the process, and producing formate (89). Formate also weakly binds to the Gpr41 and Gpr43 receptors (36).
Several species of bacteria, specifically from the Bacteroides and Enterococcus genera, express the Oxalate:formate antiporter to uptake oxalate (90). However, these species have not been found to express the appropriate enzyme, formyl-CoA:oxalate CoA-transferase, for the metabolism of oxalate (90). An untested hypothesis is that these species may uptake oxalate and, since probiotics do not colonize in the gut, together the bacteria and the oxalate may be excreted, thus preventing its uptake into the circulation.






\section{Uremic Toxins}

Uremic toxins are metabolites and waste products that are eliminated by the kidney under normal circumstances. However, as kidney function begins to decline, the kidney is unable to excrete these toxins efficiently and appropriately, resulting in their accumulation. Several uremic toxins, namely $p$-Cresol and indoxyl sulfate, are produced by gut microbes and are uptaken into the circulation where they can exhibit detrimental renal and cardiovascular effects.

A major producer of $p$-Cresol is the pathogenic bacterium Clostridium difficile (91). $p$-Cresol, or $p$-cresyl sulfate after it has been conjugated by gut microbes, reduces renal function by means of oxidative stress to induce damage $(92,93)$. It has been proposed that the microbiota-derived $p$-Cresol or $p$-cresyl sulfate can increase arterial stiffness $(94,95)$ and activate the intrarenal RAS (96). Indoxyl sulfate has also been associated with activation of the intrarenal RAS (96). Thus, these two uremic toxins have the potential to increase blood pressure not only through RASinduced renal fibrosis and impaired blood pressure regulation, but also directly through the RAS and angiotensin II. However, a study strictly assessing the effect of $p$-Cresol and indoxyl sulfate supplementation on blood pressure is lacking to validate this. Both indoxyl sulfate and $p$-cresyl sulfate also contribute to inflammation as they have been associated with increased serum pro-inflammatory cytokine expression, including IL-6 for $p$ cresyl sulfate and IL-6, TNF- $\alpha$, and IFN- $\gamma$ for indoxyl sulfate (92, 95). Importantly, while the microbiome is protective of kidney disease, production of uremic toxins by certain bacteria can exacerbate kidney disease and have cardiovascular consequences that contribute to undesirable effects on blood pressure.

\section{ADDITIONAL DIETARY BIOACTIVE MOLECULES WITH HYPOTENSIVE EFFECTS}

In addition to the factors described above, there are numerous other molecules that may contribute to the hypotensive effects conferred by the gut microbiome. A review by Dave et al. (97) details several proteins with renin inhibitor, ACE inhibitor, and anti-oxidant activity. Notably, some of these proteins include mucins, cholecystokinin, gastrin, somatostatin, and gastric inhibitory peptide among many more. Although these other molecules are known to have hypotensive effects, research surrounding these effects and their production or metabolism by specific gut microbes is limited compared to those described in more detail above. Figure 1 proposes an illustrated mechanism for gut-derived metabolites in lowering blood pressure. Table 1 describes the general functions of the metabolites listed in this review supported by human and animal studies.

\section{IMPACT OF GUT MICROBIOTA-DERIVED METABOLITES ON HYPERTENSION VIA IMMUNE MECHANISMS}

The lamina propria of the gut houses the largest proportion of immune cells in the body, especially $\mathrm{T}$ cells $(119,120)$. Some consider hypertension to be an autoimmune disorder, and there is a plethora of evidence to support this claim (121-123). The close relationship between the gut microbiota and differentiating immune cells may be a significant component in understanding and treating hypertension. For instance, circulating $\mathrm{T}_{\mathrm{H}} 17$ cells are significantly higher in hypertensive patients compared to controls (124). $\mathrm{T}_{\mathrm{H}} 17$ cells release the cytokine IL-17A which can have numerous effects in hypertension, such as increased salt retention that would contribute to an elevated blood volume (125). High salt can also promote activation of organum vasculosum laminae terminalis (OVLT) in the brain and stimulate yet another mechanism for central sympathetic hyperactivity (126). In addition, lesioning of the OVLT in animal models of salt-induced hypertension attenuates the increase in blood pressure (127).

\section{Indoles}

In the context of inflammation in hypertension, indoles can inhibit $\mathrm{T}_{\mathrm{H}} 17$ cells and suppress the release of IL-17A, thus reducing sodium retention (128). In addition to this, indoles can bind to aryl hydrocarbon receptor precursor (AhR), half of a heterodimer nuclear receptor that modifies gene expression in $\mathrm{T}$ cells. Through this mechanism, indoles promote IL-10 release from regulatory $\mathrm{T}$ cells (Tregs) and suppress $\mathrm{T}_{\mathrm{H}} 17$ responses $(106,107)$. IL-10 is an anti-inflammatory cytokine that can improve gut barrier function by reducing gut inflammation (129). Gut microbes that express the indole-3-glycerol phosphate synthase, indole-3-glucerol phosphate lyase, and indole synthase enzymes may be able to produce indole and potentially have beneficial hypotensive effects.

\section{Butyrate, Acetate, and Propionate}

While SCFAs have many metabolic effects, they are also able to ameliorate hypertension via immune-mediated mechanisms. Butyrate stabilizes hypoxia-inducible factor-1 (HIF-1), which can promote vascularization to reduce blood pressure $(99,130,131)$. Additionally, HIF-1 can improve intestinal epithelial barrier integrity through lymphocytic immune responses and reduce uncontrolled permeability $(99,132)$. Moreover, Park et al. (100) showed that sodium butyrate, as well as sodium phenylbutyrate and sodium phenylacetate, are able to potently increase IL-10 and decrease IL- 6 , TNF- $\alpha$, and IFN $\gamma$-induced iNOS in murine macrophages in vitro.

The SCFAs have been described to affect histone deacetylase (HDAC) activity. Specifically, propionate and butyrate can promote colonic Treg proliferation and differentiation by altering HDAC activity to affect gene expression $(101,102)$. On the other hand, acetate can ameliorate colonic inflammation through Gpr43 receptors via suppression of pro-inflammatory cytokines, including IL-12 and TNF- $\alpha$, and promoting anti-inflammatory signals, such as IL-10 (98).

\section{Bile Acids}

Bile acid metabolites can also contribute to immune homeostasis and limit systemic damage that is seen in inflammatory diseases. For example, secondary bile acids can act as TGR5 ligands to reduce pro-inflammatory cytokine production, including IL12 and TNF- $\alpha$, in macrophages and dendritic cells (104, 133). 
TABLE 1 | A summary of gut-derived metabolites and their general functions in hypertension.

$\begin{array}{lll}\text { Metabolite } \quad \text { Actions in hypertension } & \text { Studie }\end{array}$

\section{Short chain fatty acids}

Acetate

- Parasympathetic activity

Animal: $(35,37,98)$

- Butyrate production and prevents butyrate metabolism

- Anti-inflammatory

- Promotes release of anti-inflammatory cytokines (e.g., IL-10) and suppresses release of pro-inflammatory cytokines (e.g., IL-12 and TNF- $\alpha$ )

Butyrate

- Anti-inflammatory properties

- Histone deacetylase activity

- Promotes release of anti-inflammatory cytokines (e.g., IL-10) and suppresses release of pro-inflammatory cytokines (e.g., IL-6, TNF- $\alpha$, and IFN $\gamma$-induced iNOS)

Animal:

(10, 14, 24, 25, 28, 29, 31, 53, 99-

101)

- Promotes intestinal barrier function

- Capable of heart rate reduction

- Intestinal 5-HT synthesis (chronically)

- Limits sympathetic tone in peripheral vasculature

- Reduces norepinephrine production

- Capable of vasodilation

- Suppresses angiotensin II production and action by inhibition of the intrarenal RAS

- Intracerebroventricular injection directly reduces blood pressure centrally

- Promotes vascularization

\begin{tabular}{|c|c|c|}
\hline Lactate & - Butyrate production & \\
\hline Isovalerate & - May have anti-hypertensive effects via the gut-brain axis & \\
\hline Propionate & $\begin{array}{l}\text { - Dose dependent pro- and anti-hypertensive properties } \\
\circ \text { G-protein coupled receptor and T-cell dependent mechanisms } \\
\text { - Anti-inflammatory properties } \\
\circ \text { Reduces } T_{H} 17 \text { cell expression }\end{array}$ & Animal: $(38-40,101,102)$ \\
\hline GABA & $\begin{array}{l}\text { - Anti-hypertensive via the gut-brain axis } \\
\text { - Anti-inflammatory }\end{array}$ & Animal: (44-46) \\
\hline Histamine & $\begin{array}{l}\text { - Strong vasodilator } \\
\text { - Reduces blood volume by fluid extravasation } \\
\text { - Inhibits inflammatory actions of LPS } \\
\text { - Maintains intestinal barrier activity } \\
\text { - Counteracts the actions of angiotensin II in the heart } \\
\text { - Increases heart rate }\end{array}$ & Animal: $(62,64)$ \\
\hline TMAO & $\begin{array}{l}\text { - Supports hypertensive effects of an angiotensin II challenge } \\
\text { - Reduces primary bile acid synthesis } \\
\text { - Promotes hyperlipidemia } \\
\text { - Increases endothelial inflammation } \\
\text { - Suppresses vasodilation } \\
\text { - Reduces production of reactive oxygen species } \\
\text { - Prevents vascular injury }\end{array}$ & $\begin{array}{l}\text { Animal: }(67,68,71,72) \\
\text { Human: }(69,73)\end{array}$ \\
\hline Arachidonic acid & $\begin{array}{l}\text { - Pro-inflammatory in male mice; anti-inflammatory in female mice } \\
\text { - Protective of butyrate-producing bacteria and upregulates Gpr41 receptors } \\
\text { - Reduces corticosterone in rats }\end{array}$ & Animal: $(76,77)$ \\
\hline
\end{tabular}


TABLE 1 | Continued

\begin{tabular}{|c|c|c|}
\hline Metabolite & Actions in hypertension & Studies \\
\hline \multicolumn{3}{|l|}{ Uremic toxins } \\
\hline p-Cresol & $\begin{array}{l}\text { - Induces renal damage by oxidative stress } \\
\text { - Increases arterial stiffness } \\
\text { - Activates intrarenal RAS } \\
\text { - Pro-inflammatory } \\
\text { ○ Promotes IL-6 expression }\end{array}$ & $\begin{array}{l}\text { Animal: }(92,95,96) \\
\text { Human: }(93,94)\end{array}$ \\
\hline Indoxyl sulfate & $\begin{array}{l}\text { - Activates intrarenal RAS } \\
\text { - Pro-inflammatory } \\
\text { ○ Promotes IL-6, TNF- } \alpha \text {, and IFN- } \gamma \text { expression }\end{array}$ & $\begin{array}{l}\text { Animal: }(92,96) \\
\text { Human: }(95)\end{array}$ \\
\hline \multicolumn{3}{|l|}{ Polyamines } \\
\hline Spermidine & $\begin{array}{l}\text { - Dietary spermidine decreases blood pressure, and vasodilates blood vessels } \\
\text { - Reduces systemic inflammation }\end{array}$ & $\begin{array}{l}\text { Animal: }(108,109) \\
\text { Human: }(110)\end{array}$ \\
\hline Spermine & $\begin{array}{l}\text { - Decreases blood pressure intravenously } \\
\text { - Anti-inflammatory } \\
\text { ○ Suppresses IL-12, IL-18, and IFN } \gamma \text { expression } \\
\text { - Promotes IL-10 expression } \\
\text { - Oral spermine increases blood pressure }\end{array}$ & Animal: (111-113) \\
\hline Cadaverine & $\begin{array}{l}\text { - Decreases blood pressure intravenously } \\
\text { - Pro-inflammatory } \\
\text { ○Intraperitoneal injection induces systemic inflammatory response }\end{array}$ & Animal: $(111,114)$ \\
\hline Putrescine & $\begin{array}{l}\text { - Decreases blood pressure intravenously } \\
\text { - Anti-inflammatory } \\
\circ \text { Suppresses IL-18 and LPS-induced inflammation } \\
\circ \text { Dietary putrescine reduces pro-inflammatory infiltration into tissues } \\
\text { - Pro-inflammatory } \\
\circ \text { Intraperitoneal injection induces systemic inflammatory response }\end{array}$ & Animal: $(111,114,115)$ \\
\hline Polysaccharide A & $\begin{array}{l}\text { - Anti-inflammatory } \\
\circ \text { Stimulates IL-10 release } \\
\circ \text { Supresses } T_{H} 17 \text { responses }\end{array}$ & Animal: (116-118) \\
\hline
\end{tabular}

Furthermore, secondary bile acids can bind to the pregnane $\mathrm{X}$ (PXR) and farnesoid X receptors (FXR) to reduce inflammatory tissue damage $(103,105)$. However, it should be noted that the exact mechanism and the degree to which secondary bile acids contribute reductions in inflammation through PXR and FXR are not quite known and further research should be conducted. The anti-inflammatory actions of secondary bile acids have yet to be investigated extensively in the context of hypertension, but there is the potential that secondary bile acids could attenuate the inflammation observed in hypertension.

\section{Polyamines}

The polyamines are not frequently discussed when evaluating disease states, however, they are quite present in the gut due to microbial fermentation and can have a slew of effects in the body, especially in immune homeostasis. The four main polyamines are spermidine, spermine, cadaverine, and putrescine.

1. Spermidine

Dietary spermidine in human models has been shown to reduce blood pressure and arterial stiffness by directly increasing arginine bioavailability and $\mathrm{NO}$, which vasodilates blood vessels (108-110). In addition to this, plasma TNF$\alpha$ and systemic inflammation are reduced by spermidine intake (108).

\section{Spermine}

When administered intravenously into rats, spermine reduced blood pressure in a dose-dependent manner (111). However, in rat models with oral spermine administration, there is evidence of an increase in blood pressure (112). The reason for the discrepancy in intravenous versus oral spermine on blood pressure is unclear. Research into the effects of polyamine supplementation and mechanisms of action in the context of hypertension is limited and must be explored further. Regarding inflammatory mechanisms, spermine is able to reduce inflammation by lowering production of IL-12 and interferon- $\gamma$ (IFN $\gamma)$, while increasing IL-10 production (113). Similarly to histamine, both spermine and putrescine can suppress the cleavage of protease caspase- 1 and reduce secretion of IL-18 (63). Notably, spermine can be converted to spermidine by spermine oxidase to have additional effects.

3. Cadaverine and Putrescine

When administered intravenously into rats, cadaverine, and putrescine both reduced blood pressure in a dosedependent manner (111). However, in human subjects, dietary putrescine had no significant effect on blood pressure (109). Conversely, there is limited research into direct effects of cadaverine on blood pressure in human subjects. In rabbits, intraperitoneal injection of cadaverine and putrescine induced a systemic inflammatory response 
(114). However, dietary putrescine reduced pro-inflammatory cytokine infiltration into the intestinal walls of piglets (115). In vitro, putrescine ameliorates LPS-induced inflammation and pro-inflammatory cytokine release (115). Through reductions of inflammation, and specifically LPS-induced inflammation in the gut, putrescine has the potential to be protective against development of "leaky gut" and bacterial translocation. While the intravenous anti-hypertensive mechanisms of cadaverine and putrescine remain elusive, anti-inflammatory properties are evident with dietary supplementation.

\section{Polysaccharide A}

Little is known about which bacterial species produce or express polysaccharide A (PSA), however B. fragilis is widely accepted to express it and can utilize PSA to interact with other microbes and host cells (134). In immune homeostasis, PSA can bind to tolllike receptor-2 (TLR2) on CD4 ${ }^{+} \mathrm{T}$ cells to stimulate IL-10 release from regulatory Tregs and suppress $\mathrm{T}_{\mathrm{H}} 17$ responses (116-118). As discussed above, hypertensive patients express more $\mathrm{T}_{\mathrm{H}} 17$ cells that can increase blood pressure by salt retention.

\section{CONCLUSION}

Through interaction with the gut, brain, kidneys, liver, heart, vasculature, and host immunity, the gut microbiota and the

\section{REFERENCES}

1. Virani SS, Alvaro A, Aparicio HJ, Benjamin EJ, Bittencourt MS, Callaway CW, et al. Heart disease and stroke statistics-2021 update. Circulation. (2021) 143:e254-743. doi: 10.1161/CIR.0000000000000950

2. Palmu J, Salosensaari A, Havulinna AS, Cheng $S$, Inouye $M$, Jain $M$, et al. Association between the gut microbiota and blood pressure in a population cohort of 6953 individuals. J Am Heart Assoc. (2020) 9:e016641. doi: 10.1161/JAHA.120.016641

3. Dan X, Mushi Z, Baili W, Han L, Enqi W, Huanhu Z, et al. Differential analysis of hypertension-associated intestinal microbiota. Int J Med Sci. (2019) 16:872-81. doi: 10.7150/ijms.29322

4. Li J, Zhao F, Wang Y, Chen J, Tao J, Tian G, et al. Gut microbiota dysbiosis contributes to the development of hypertension. Microbiome. (2017) 5:14. doi: 10.1186/s40168-016-0222-x

5. Liu J, An N, Ma C, Li X, Zhang J, Zhu W, et al. Correlation analysis of intestinal flora with hypertension. Exp Ther Med. (2018) 16:232530. doi: 10.3892/etm.2018.6500

6. Sun S, Lulla A, Sioda M, Winglee K, Wu MC, Jacobs DR, et al. Gut microbiota composition and blood pressure: the CARDIA study. Hypertension. (2019) 73:998-1006. doi: 10.1161/HYPERTENSIONAHA.118.12109

7. Moghadamrad S, Mccoy KD, Geuking MB, Sägesser H, Kirundi J, Macpherson AJ, et al. Attenuated portal hypertension in germ-free mice: function of bacterial flora on the development of mesenteric lymphatic and blood vessels. Hepatology. (2015) 61:1685-95. doi: 10.1002/hep. 27698

8. Lee C, Kim BG, Kim JH, Chun J, Im JP, Kim JS. Sodium butyrate inhibits the NF-кB signaling pathway and histone deacetylation, and attenuates experimental colitis in an IL-10 independent manner. Int Immunopharmacol. (2017) 51:47-56. doi: 10.1016/j.intimp.2017. 07.023

9. Zhang M, Zhou Q, Dorfman RG, Huang X, Fan T, Zhang H, et al. Butyrate inhibits interleukin-17 and generates Tregs to ameliorate colorectal colitis in rats. BMC Gastroenterol. (2016) 16:84. doi: 10.1186/s12876-016-0500-x metabolites which are produced, consumed, and otherwise manipulated can have widespread effects in the body. There are still many topics of research that remain to be investigated in this area, but what has become clear is that the gut microbiome is a complex and highly interactive system. For the treatment of disease states, a single "one-size fits all" metabolite or bacterial strain is unlikely to restore the extensive metabolic activity that is lost with intestinal dysbiosis in hypertension. Instead, probiotic supplementation using several bacterial strains that produce or reduce the production of appropriate metabolites to elicit a net antihypertensive effect is a strong potential treatment strategy for hypertension management. Additional targeted therapies, such as phage therapy, that specifically deplete or mitigate the growth of certain bacterial strains may also prove to be useful. Characterization of interactions between several bacterial strains will be important going forward to determine the best combinations of probiotic bacteria and metabolites for these new therapies.

\section{AUTHOR CONTRIBUTIONS}

TC performed the literature review, any relevant data collection, data analysis, and wrote the manuscript and involved in the critical revision of the manuscript and approved the final version.

10. Wang RX, Lee JS, Campbell EL, Colgan SP. Microbiota-derived butyrate dynamically regulates intestinal homeostasis through regulation of actinassociated protein synaptopodin. Proc Natl Acad Sci U S A. (2020) 117:11648-57. doi: 10.1073/pnas.1917597117

11. Peng L, Li ZR, Green RS, Holzman IR, Lin J. Butyrate enhances the intestinal barrier by facilitating tight junction assembly via activation of AMP-activated protein kinase in Caco-2 cell monolayers. J Nutr. (2009) 139:1619-25. doi: 10.3945/jn.109.104638

12. Tabat MW, Marques TM, Markgren M, Löfvendahl L, Brummer RJ, Wall R. Acute effects of butyrate on induced hyperpermeability and tight junction protein expression in human colonic tissues. Biomolecules. (2020) 10:766. doi: 10.3390/biom 10050766

13. Kim S, Goel R, Kumar A, Qi Y, Lobaton G, Hosaka K, et al. Imbalance of gut microbiome and intestinal epithelial barrier dysfunction in patients with high blood pressure. Clin Sci. (2018) 132:701-18. doi: 10.1042/CS20180087

14. Onyszkiewicz M, Gawrys-Kopczynska M, Konopelski P, Aleksandrowicz M, Sawicka A, Kozniewska E, et al. Butyric acid, a gut bacteria metabolite, lowers arterial blood pressure via colon-vagus nerve signaling and GPR41/43 receptors. Pflugers Arch Eu J Physiol. (2019) 471:144153. doi: 10.1007/s00424-019-02322-y

15. Reigstad CS, Salmonson CE, Rainey JF, Szurszewski JH, Linden DR, Sonnenburg JL, et al. Gut microbes promote colonic serotonin production through an effect of short-chain fatty acids on enterochromaffin cells. FASEB J. (2015) 29:1395-403. doi: 10.1096/fj.14-259598

16. Kuhns VLH, Sanchez J, Sarver DC, Khalil Z, Rajkumar P, Marr $\mathrm{KA}$, et al. Characterizing novel olfactory receptors expressed in the murine renal cortex. Am J Physiol Renal Physiol. (2019) 317:F172F86. doi: 10.1152/ajprenal.00624.2018

17. Bellono NW, Bayrer JR, Leitch DB, Castro J, Zhang C, O'Donnell TA, et al. Enterochromaffin cells are gut chemosensors that couple to sensory neural pathways. Cell. (2017) 170:10-1. doi: 10.1016/j.cell.2017.05.034

18. Browning KN. Role of central vagal 5-HT3 receptors in gastrointestinal physiology and pathophysiology. Front Neurosci. (2015) 9:413. doi: $10.3389 /$ fnins.2015.00413 
19. Talman WT, Granata AR, Reis DJ. Glutamatergic mechanisms in the nucleus tractus solitarius in blood pressure control. Fed Proc. (1984) 43:39-44.

20. Hosford PS, Mifflin SW, Ramage AG. 5-Hydroxytryptamine-Mediated neurotransmission modulates Spontaneous and Vagal-Evoked glutamate release in the Nucleus of the solitary tract effect of uptake blockade. $J$ Pharmacol Exp Ther. (2014). 349:288-96. doi: 10.1124/jpet.113.211334

21. Martin AM, Lumsden AL, Young RL, Jessup CF, Spencer NJ, Keating DJ. Regional differences in nutrient-induced secretion of gut serotonin. Physiol Rep. (2017) 5:e13199. doi: 10.14814/phy2.13199

22. Yano JM, Yu K, Donaldson GP, Shastri GG, Ann P, Ma L, et al. Indigenous bacteria from the gut microbiota regulate host serotonin biosynthesis. Cell. (2015) 161:264-76. doi: 10.1016/j.cell.2015.02.047

23. Huzoor-Akbar, Chen NY, Fossen DV, Wallace D. Increased vascular contractile sensitivity to serotonin in spontaneously hypertensive is linked with increased turnover of phosphoinositide. Life Sci. (1989) 45:57783. doi: 10.1016/0024-3205(89)90042-8

24. Arányi T, Sarkis C, Berrard S, Sardin K, Siron V, Khalfallah O, et al. Sodium butyrate modifies the stabilizing complexes of tyrosine hydroxylase mRNA. Biochem Biophys Res Commun. (2007) 359:159. doi: 10.1016/j.bbrc.2007.05.025

25. Aaronson PI, McKinnon W, Poston L. Mechanism of butyrate-induced vasorelaxation of rat mesenteric resistance artery. Br J Pharmacol. (1996) 117:365-71. doi: 10.1111/j.1476-5381.1996.tb15200.x

26. Xu J, Cheema MU, Pluznick JL. Uncovering the physiological role of olfactory receptor 558 (Olfr558) in the vasculature. FASEB J. (2020) 34:1. doi: 10.1096/fasebj.2020.34.s1.03095

27. Pronin A, Levay K, Velmeshev D, Faghihi M, Shestopalov VI, Slepak VZ. Expression of olfactory signaling genes in the eye. PLoS One. (2014) 9:e96435. doi: 10.1371/journal.pone.0096435

28. Wang L, Zhu Q, Lu A, Liu X, Zhang L, Xu C, et al. Sodium butyrate suppresses angiotensin II-induced hypertension by inhibition of renal (pro)renin receptor and intrarenal renin-Angiotensin system. J Hypertens. (2017) 35:1899-908. doi: 10.1097/HJH.0000000000001378

29. Yang T, Magee KL, Colon-Perez LM, Larkin R, Liao YS, Balazic E, et al. Impaired butyrate absorption in the proximal colon, low serum butyrate and diminished central effects of butyrate on blood pressure in spontaneously hypertensive rats. Acta Physiol. (2019) 226:e13256. doi: 10.1111/apha.13256

30. Zubcevic J, Richards EM, Yang T, Kim S, Sumners C, Pepine CJ, et al. Impaired autonomic nervous system-microbiome circuit in hypertension a premise for hypertension therapy. Circ Res. (2019) 125:104-16. doi: 10.1161/CIRCRESAHA.119.313965

31. Toral M, Robles-Vera I, de La Visitación N, Romero M, Yang T, Sánchez $\mathrm{M}$, et al. Critical role of the interaction gut microbiota-sympathetic nervous system in the regulation of blood pressure. Front Physiol. (2019) 10:231. doi: 10.3389/fphys.2019.00231

32. Louis P, Flint HJ. Formation of propionate and butyrate by the human colonic microbiota. Environ Microbiol. (2017) 19:29-41. doi: 10.1111/1462-2920.13589

33. Louis P, Flint HJ. Diversity, metabolism and microbial ecology of butyrateproducing bacteria from the human large intestine. FEMS Microbiol Lett. (2009) 294:1-8. doi: 10.1111/j.1574-6968.2009.01514.x

34. Detman A, Mielecki D, Chojnacka A, Salamon A, Błaszczyk MK, Sikora A. Cell factories converting lactate and acetate to butyrate: Clostridium butyricum and microbial communities from dark fermentation bioreactors. Microb Cell Fact. (2019) 18:36. doi: 10.1186/s12934-019-1085-1

35. Perry RJ, Peng L, Barry NA, Cline GW, Zhang D, Cardone RL, et al. Acetate mediates a microbiome-brain- $\beta$-cell axis to promote metabolic syndrome. Nature. (2016) 534:213-7. doi: 10.1038/nature18309

36. Brown AJ, Goldsworthy SM, Barnes AA, Eilert MM, Tcheang L, Daniels $\mathrm{D}$, et al. The orphan G protein-coupled receptors GPR41 and GPR43 are activated by propionate and other short chain carboxylic acids. J Biol Chem. (2003) 278:11312-9. doi: 10.1074/jbc.M211609200

37. Marques FZ, Nelson E, Chu PY, Horlock D, Fiedler A, Ziemann $M$, et al. High-fiber diet and acetate supplementation change the gut microbiota and prevent the development of hypertension and heart failure in hypertensive mice. Circulation. (2017) 135:964-77. doi: 10.1161/CIRCULATIONAHA.116.024545
38. Bartolomaeus H, Balogh A, Yakoub M, Homann S, Markó L, Höges S, et al. Short-chain fatty acid propionate protects from hypertensive cardiovascular damage. Circulation. (2019) 139:1407-21. doi: 10.1161/CIRCULATIONAHA.118.036652

39. Pluznick JL, Protzko RJ, Gevorgyan H, Peterlin Z, Sipos A, Han J, et al. Olfactory receptor responding to gut microbiota-derived signals plays a role in renin secretion and blood pressure regulation. Proc Natl Acad Sci U S A. (2013) 110:4410-5. doi: 10.1073/pnas.1215927110

40. Natarajan N, Hori D, Flavahan S, Steppan J, Flavahan NA, Berkowitz DE, et al. Microbial short chain fatty acid metabolites lower blood pressure via endothelial G protein-coupled receptor 41. Physiol Genomics. (2016) 48:826-34. doi: 10.1152/physiolgenomics.00089.2016

41. Mishra AK, Kumar SS, Ghosh AR. Probiotic Enterococcus faecalis AG5 effectively assimilates cholesterol and produces fatty acids including propionate. FEMS Microbiol Lett. (2019) 366:fnz039. doi: 10.1093/femsle/fnz039

42. Jeong S, Lee Y, Yun CH, Park OJ, Han SH. Propionate, together with triple antibiotics, inhibits the growth of Enterococci. J Microbiol. (2019) 57:1019-24. doi: 10.1007/s12275-019-9434-7

43. Louis P, Hold GL, Flint HJ. The gut microbiota, bacterial metabolites and colorectal cancer. Nat Rev Microbiol. (2014) 12:661-72. doi: 10.1038/nrmicro3344

44. Kimura M, Hayakawa K, Sansawa H. Involvement of $\gamma$-aminobutyric acid (GABA) B receptors in the hypotensive effect of systemically administered GABA in spontaneously hypertensive rats. Jpn J Pharmacol. (2002) 89:38894. doi: $10.1254 /$ jjp. 89.388

45. Matsumoto M, Ooga T, Kibe R, Aiba Y, Koga Y, Benno Y. Colonic absorption of low-molecular-weight metabolites influenced by the intestinal microbiome: a pilot study. PLoS One. (2017) 12:e0169207. doi: 10.1371/journal.pone.0169207

46. Page AJ, Blackshaw LA. GABA(B) receptors inhibit mechanosensitivity of primary afferent endings. J Neurosci. (1999) 19:8597602. doi: 10.1523/JNEUROSCI.19-19-08597.1999

47. Bajic SS, Djokic J, Dinic M, Veljovic K, Golic N, Mihajlovic S, et al. GABAproducing natural dairy isolate from artisanal zlatar cheese attenuates gut inflammation and strengthens gut epithelial barrier in vitro. Front Microbiol. (2019) 10:527. doi: 10.3389/fmicb.2019.00527

48. Zanoli L, Rastelli S, Inserra G, Castellino P. Arterial structure and function in inflammatory bowel disease. World J Gastroenterol. (2015) 21:1130411. doi: 10.3748/wjg.v21.i40.11304

49. Winter SE, Lopez CA, Bäumler AJ. The dynamics of gut-associated microbial communities during inflammation. EMBO Rep. (2013) 14:31927. doi: 10.1038/embor.2013.27

50. Edwards JM, Roy S, Tomcho JC, Schreckenberger ZJ, Chakraborty S, Bearss NR, et al. Microbiota are critical for vascular physiology: germ-free status weakens contractility and induces sex-specific vascular remodeling in mice. Vascul Pharmacol. (2020) 125-126:106633. doi: 10.1016/j.vph.2019.106633

51. Park EJ, Thomson ABR, Clandinin MT. Protection of intestinal occludin tight junction protein by dietary gangliosides in lipopolysaccharideinduced acute inflammation. J Pediatr Gastroenterol Nutr. (2010) 50:3218. doi: 10.1097/MPG.0b013e3181ae2ba0

52. Guo S, Al-Sadi R, Said HM, Ma TY. Lipopolysaccharide causes an increase in intestinal tight junction permeability in vitro and in vivo by inducing enterocyte membrane expression and localization of TLR-4 and CD14. Am J Pathol. (2013) 182:375-87. doi: 10.1016/j.ajpath.2012.10.014

53. Yan H, Ajuwon KM. Butyrate modifies intestinal barrier function in IPEC-J2 cells through a selective upregulation of tight junction proteins and activation of the Akt signaling pathway. PLoS One. (2017) 12:e0179586. doi: 10.1371/journal.pone.0179586

54. Rodríguez-Laiz GP, Zapater P, Melgar P, Alcázar C, Franco M, Giménez P, et al. Bacterial DNA translocation contributes to systemic inflammation and to minor changes in the clinical outcome of liver transplantation. Sci Rep. (2019) 9:835. doi: 10.1038/s41598-018-36904-0

55. Zhou X, Li J, Guo J, Geng B, Ji W, Zhao Q, et al. Gut-dependent microbial translocation induces inflammation and cardiovascular events after ST-elevation myocardial infarction. Microbiome. (2018) 6:66. doi: 10.1186/s40168-018-0441-4 
56. Salguero M, Al Obaide M, Singh R, Siepmann T, Vasylyeva T. Dysbiosis of Gram negative gut microbiota and the associated serum lipopolysaccharide exacerbates inflammation in type 2 diabetic patients with chronic kidney disease. Exp Ther Med. (2019) 18:3461. doi: 10.3892/etm.2019.7943

57. Banks WA, Robinson SM. Minimal penetration of lipopolysaccharide across the murine blood-brain barrier. Brain Behav Immun. (2010) 24:1029. doi: 10.1016/j.bbi.2009.09.001

58. Santisteban MM, Kim S, Pepine CJ, Raizada MK. Brain-gut-bone marrow axis: Implications for hypertension and related therapeutics. Circ Res. (2016) 118:1327-36. doi: 10.1161/CIRCRESAHA.116.307709

59. Santisteban MM, Ahmari N, Carvajal JM, Zingler MB, Qi Y, Kim S, et al. Involvement of bone marrow cells and neuroinflammation in hypertension. Circ Res. (2015) 117:178-91. doi: 10.1161/CIRCRESAHA.117.305853

60. Zhang ZH, Yu Y, Wei SG, Felder RB. Centrally administered lipopolysaccharide elicits sympathetic excitation via $\mathrm{NAD}(\mathrm{P}) \mathrm{H}$ oxidasedependent mitogen-activated protein kinase signaling. J Hypertens. (2010) 28:806-16. doi: 10.1097/HJH.0b013e3283358b6e

61. Kaliner M, Sigler R, Summers R, Shelhamer JH. Effects of infused histamine: analysis of the effects of $\mathrm{H}-1$ and $\mathrm{H}-2$ histamine receptor antagonists on cardiovascular and pulmonary responses. J Allergy Clin Immunol. (1981) 68:365-71. doi: 10.1016/0091-6749(81)90134-2

62. Ashina K, Tsubosaka Y, Nakamura T, Omori K, Kobayashi K, Hori $\mathrm{M}$, et al. Histamine induces vascular hyperpermeability by increasing blood flow and endothelial barrier disruption in vivo. PLoS One. (2015) 10:e0132367. doi: 10.1371/journal.pone.0132367

63. Blander JM, Longman RS, Iliev ID, Sonnenberg GF, Artis D. Regulation of inflammation by microbiota interactions with the host. Nat Immunol. (2017) 18:851-60. doi: 10.1038/ni.3780

64. Hashikawa-Hobara N, Chan NYK, Levi R. Histamine 3 receptor activation reduces the expression of neuronal angiotensin II type 1 receptors in the heart. J Pharmacol Exp Ther. (2012) 340:185-91. doi: 10.1124/jpet.111.187765

65. Kidd M, Modlin IM, Gustafsson BI, Drozdov I, Hauso O, Pfragner R. Luminal regulation of normal and neoplastic human EC cell serotonin release is mediated by bile salts, amines, tastants, and olfactants. Am J Physiol Gastrointest Liver Physiol. (2008) 295:G26072. doi: 10.1152/ajpgi.00056.2008

66. Alemi F, Poole DP, Chiu J, Schoonjans K, Cattaruzza F, Grider JR, et al. The receptor TGR5 mediates the prokinetic actions of intestinal bile acids and is required for normal defecation in mice. Gastroenterology. (2013) 144:145-54. doi: 10.1053/j.gastro.2012.09.055

67. Koeth RA, Wang Z, Levison BS, Buffa JA, Org E, Sheehy BT, et al. Intestinal microbiota metabolism of 1-carnitine, a nutrient in red meat, promotes atherosclerosis. Nat Med. (2013) 19:576-85. doi: 10.1038/nm.3145

68. Li T, Chen Y, Gua C, Li X. Elevated circulating trimethylamine Noxide levels contribute to endothelial dysfunction in aged rats through vascular inflammation and oxidative stress. Front Physiol. (2017) 8:350. doi: 10.3389/fphys.2017.00350

69. Chou RH, Chen CY, Chen IC, Huang HL, Lu YW, Kuo CS, et al. Trimethylamine $\mathrm{N}$-oxide, circulating endothelial progenitor cells, and endothelial function in patients with stable angina. Sci Rep. (2019) 9:4249. doi: 10.1038/s41598-019-40638-y

70. Barrett EL, Kwan HS. Bacterial reduction of trimethylamine oxide. Annu Rev Microbiol. (1985). 39:131-49. doi: 10.1146/annurev.mi.39.100185.001023

71. Suzuki S, Kubo A, Shinano H, Takama K. Inhibition of the electron transport system in Staphylococcus aureus by trimethylamine-N-oxide. Microbios. (1992) 71:145-8.

72. Ufnal M, Jazwiec R, Dadlez M, Drapala A, Sikora M, Skrzypecki J. Trimethylamine-N-oxide: a carnitine-derived metabolite that prolongs the hypertensive effect of angiotensin II in rats. Can J Cardiol. (2014) 30:17005. doi: 10.1016/j.cjca.2014.09.010

73. Fukami K, Yamagishi SI, Sakai K, Kaida Y, Yokoro M, Ueda S, et al. Oral $\mathrm{L}$-carnitine supplementation increases trimethylamine-N-oxide but reduces markers of vascular injury in hemodialysis patients. J Cardiovasc Pharmacol. (2015) 65:289-95. doi: 10.1097/FJC.0000000000000197

74. Virdis A, Dell'Agnello $U$, Taddei S. Impact of inflammation on vascular disease in hypertension. Maturitas. (2014) 78:17983. doi: $10.1016 /$ j.maturitas.2014.04.012
75. Alexander RW. Hypertension and the pathogenesis of atherosclerosis: oxidative stress and the mediation of arterial inflammatory response: a new perspective. Hypertension. (1995) 25:155-61. doi: 10.1161/01.HYP.25.2.155

76. Zhuang P, Shou Q, Lu Y, Wang G, Qiu J, Wang J, et al. Arachidonic acid sex-dependently affects obesity through linking gut microbiota-driven inflammation to hypothalamus-adipose-liver axis. Biochim Biophys Acta. (2017) 1863:2715-26. doi: 10.1016/j.bbadis.2017.07.003

77. Yan $X$, Jin J, Su X, Yin X, Gao J, Wang $X$, et al. Intestinal flora modulates blood pressure by regulating the synthesis of intestinal-derived corticosterone in high salt-induced hypertension. Circ Res. (2020) 126:83953. doi: 10.1161/CIRCRESAHA.119.316394

78. Calder PC. Polyunsaturated fatty acids, inflammatory processes and inflammatory bowel diseases. Mol Nutr Food Res. (2008) 52:88597. doi: $10.1002 / \mathrm{mnfr} .200700289$

79. Huć T, Nowinski A, Drapala A, Konopelski P, Ufnal M. Indole and indoxyl sulfate, gut bacteria metabolites of tryptophan, change arterial blood pressure via peripheral and central mechanisms in rats. Pharmacol Res. (2018) 130:172-9. doi: 10.1016/j.phrs.2017.12.025

80. Psichas A, Sleeth ML, Murphy KG, Brooks L, Bewick GA, Hanyaloglu AC, et al. The short chain fatty acid propionate stimulates GLP-1 and PYY secretion via free fatty acid receptor 2 in rodents. Int J Obes. (2015) 39:424-9. doi: 10.1038/ijo.2014.153

81. Christiansen CB, Gabe MBN, Svendsen B, Dragsted LO, Rosenkilde MM, Holst JJ. The impact of short-chain fatty acids on GLP-1 and PYY secretion from the isolated perfused rat colon. Am J Physiol. (2018) 315:G5365. doi: 10.1152/ajpgi.00346.2017

82. Sun F, Wu S, Guo S, Yu K, Yang Z, Li L, et al. Impact of GLP-1 receptor agonists on blood pressure, heart rate and hypertension among patients with type 2 diabetes: a systematic review and network meta-analysis. Diabetes Res Clin Pract. (2015) 110:26-37. doi: 10.1016/j.diabres.2015. 07.015

83. Goud A, Zhong J, Peters M, Brook RD, Rajagopalan S. GLP-1 agonists and blood pressure: a review of the evidence. Curr Hypertens Rep. (2016) 18:16. doi: 10.1007/s11906-015-0621-6

84. Guyton AC, Coleman TG, Cowley AW, Scheel KW, Manning RD, Norman RA. Arterial pressure regulation. Overriding dominance of the kidneys in long-term regulation and in hypertension. Am J Med. (1972) 52:58494. doi: 10.1016/0002-9343(72)90050-2

85. Hall JE. The kidney, hypertension, and obesity. Hypertension. (2003) 41:62533. doi: 10.1161/01.HYP.0000052314.95497.78

86. Mishima E, Fukuda S, Mukawa C, Yuri A, Kanemitsu Y, Matsumoto Y, et al. Evaluation of the impact of gut microbiota on uremic solute accumulation by a CE-TOFMS-based metabolomics approach. Kidney Int. (2017) 92:63445. doi: 10.1016/j.kint.2017.02.011

87. Ermer T, Eckardt KU, Aronson PS, Knauf F. Oxalate, inflammasome, and progression of kidney disease. Curr Opin Nephrol Hypertens. (2016) 25:36371. doi: 10.1097/MNH.0000000000000229

88. Kittanamongkolchai W, Mara KC, Mehta RA, Vaughan LE, Denic A, Knoedler JJ, et al. Risk of hypertension among first-time symptomatic kidney stone formers. Clin J Am Soc Nephrol. (2017) 12:476-82. doi: 10.2215/CJN.06600616

89. Cornick NA, Allison MJ. Assimilation of oxalate, acetate, and $\mathrm{CO}_{2}$ by Oxalobacter formigenes. Can J Microbiol. (1996) 42:1081-6. doi: 10.1139/m96-138

90. Bateman A, Martin MJ, Orchard S, Magrane M, Agivetova R, Ahmad S, et al. UniProt: the universal protein knowledgebase in 2021. Nucleic Acids Res. (2021) 49:D480-D9. doi: 10.1093/nar/gkaa1100

91. Dawson L, Stabler R, Wren B. Assessing the role of p-cresol tolerance in Clostridium difficile. J Med Microbiol. (2008) 57(Pt 6):745-9. doi: 10.1099/jmm.0.47744-0

92. Watanabe H, Miyamoto Y, Honda D, Tanaka H, Wu Q, Endo M, et al. p-Cresyl sulfate causes renal tubular cell damage by inducing oxidative stress by activation of NADPH oxidase. Kidney Int. (2013) 83:58292. doi: 10.1038/ki.2012.448

93. Lin C-J, Chuang C-K, Jayakumar T, Liu H-L, Pan C-F, Wang T-J, et al. Clinical research Serum $\mathrm{p}$-cresyl sulfate predicts cardiovascular disease and mortality in elderly hemodialysis patients. Arch Med Sci. (2013) 9:6628. doi: 10.5114/aoms.2013.36901 
94. Lai Y-H, Wang C-H, Kuo C-H, Lin Y-L, Tsai J-P, Hsu B-G. Serum P-Cresyl sulfate is a predictor of central arterial stiffness in patients on maintenance hemodialysis. Toxins. (2020) 12:10. doi: 10.3390/toxins12010010

95. Rossi M, Campbell K, Johnson D, Stanton T, Vesey D, Coombes J, et al. Protein-bound uremic toxins, inflammation and oxidative stress: a crosssectional study in stage 3-4 chronic kidney disease. Arch Med Res. (2014) 45:309-17. doi: 10.1016/j.arcmed.2014.04.002

96. Sun C, Chang S, Wu M. Uremic toxins induce kidney fibrosis by activating intrarenal renin-angiotensin-aldosterone system associated epithelial-to-mesenchymal transition. PLoS One. (2012) 7:e34026. doi: 10.1371/journal.pone.0034026

97. Dave LA, Hayes M, Montoya CA, Rutherfurd SM, Moughan PJ. Human gut endogenous proteins as a potential source of angiotensin-I-converting enzyme (ACE-I)-, renin inhibitory and antioxidant peptides. Peptides. (2016) 76:30-44. doi: 10.1016/j.peptides.2015.11.003

98. Masui R, Sasaki M, Funaki Y, Ogasawara N, Mizuno M, Iida A, et al. G protein-coupled receptor 43 moderates gut inflammation through cytokine regulation from mononuclear cells. Inflamm Bowel Dis. (2013) 19:284856. doi: 10.1097/01.MIB.0000435444.14860.ea

99. Kelly CJ, Zheng L, Campbell EL, Saeedi B, Scholz CC, Bayless AJ, et al. Crosstalk between microbiota-derived short-chain fatty acids and intestinal epithelial HIF augments tissue barrier function. Cell Host Microbe. (2015) 17:662-71. doi: 10.1016/j.chom.2015.03.005

100. Park JS, Lee EJ, Lee JC, Kim WK, Kim HS. Anti-inflammatory effects of short chain fatty acids in IFN- $\gamma$-stimulated RAW 264.7 murine macrophage cells: involvement of NF- $\mathrm{BB}$ and ERK signaling pathways. Int Immunopharmacol. (2007) 7:70-7. doi: 10.1016/j.intimp.2006.08.015

101. Furusawa Y, Obata Y, Fukuda S, Endo TA, Nakato G, Takahashi D, et al. Commensal microbe-derived butyrate induces the differentiation of colonic regulatory T cells. Nature. (2013) 504:446-50. doi: 10.1038/nature12721

102. Smith PM, Howitt MR, Panikov N, Michaud M, Gallini CA, Bohlooly-Y M, et al. The microbial metabolites, short-chain fatty acids, regulate colonic $\mathrm{T}$ reg cell homeostasis. Science. (2013) 341:569-73. doi: 10.1126/science.1241165

103. Shah YM, Ma X, Morimura K, Kim I, Gonzalez FJ. Pregnane X receptor activation ameliorates DSS-induced inflammatory bowel disease via inhibition of NF-кB target gene expression. Am J Physiol. (2007) 292:G1114G22. doi: 10.1152/ajpgi.00528.2006

104. Ichikawa R, Takayama T, Yoneno K, Kamada N, Kitazume MT, Higuchi $\mathrm{H}$, et al. Bile acids induce monocyte differentiation toward interleukin12 hypo-producing dendritic cells via a TGR5-dependent pathway. Immunology. (2012) 136:153-62. doi: 10.1111/j.1365-2567.2012.03554.x

105. Renga B, Mencarelli A, Cipriani S, D’Amore C, Carino A, Bruno A, et al. The Bile acid sensor FXR is required for immune-regulatory activities of TLR-9 in intestinal inflammation. PLoS One. (2013) 8:e54472. doi: 10.1371/journal.pone.0054472

106. Apetoh L, Quintana FJ, Pot C, Joller N, Xiao S, Kumar D, et al. The aryl hydrocarbon receptor interacts with c-Maf to promote the differentiation of type 1 regulatory T cells induced by IL-27. Nat Immunol. (2010) 11:85461. doi: $10.1038 /$ ni. 1912

107. Singh NP, Singh UP, Rouse M, Zhang J, Chatterjee S, Nagarkatti PS, et al. Dietary indoles suppress delayed-type hypersensitivity by inducing a switch from proinflammatory Th17 cells to anti-inflammatory regulatory $\mathrm{T}$ cells through regulation of microRNA. J Immunol. (2016) 196:110822. doi: 10.4049/jimmunol.1501727

108. Eisenberg T, Abdellatif M, Zimmermann A, Schroeder S, Pendl T, Harger A, et al. Dietary spermidine for lowering high blood pressure. Autophagy. (2017) 13:767-9. doi: 10.1080/15548627.2017.1280225

109. Eisenberg T, Abdellatif M, Schroeder S, Primessnig U, Stekovic S, Pendl $\mathrm{T}$, et al. Cardioprotection and lifespan extension by the natural polyamine spermidine. Nat Med. (2016) 22:1428-38. doi: 10.1038/nm.4222

110. Kiechl S, Pechlaner R, Willeit P, Notdurfter M, Paulweber B, Willeit $\mathrm{K}$, et al. Higher spermidine intake is linked to lower mortality: a prospective population-based study. Am J Clin Nutr. (2018) 108:37180. doi: 10.1093/ajcn/nqy102

111. Til HP, Falke HE, Prinsen MK, Willems MI. Acute and subacute toxicity of tyramine, spermidine, spermine, putrescine and cadaverine in rats. Food Chem Toxicol. (1997) 35:337-48. doi: 10.1016/S0278-6915(97)00121-X
112. Tipnis UR, Li S. Hypertension in normotensive and hypertensive rats by spermine ingestion. Cytobios. (2001) 106(Suppl 1):85-98.

113. Haskó G, Kuhel DG, Marton A, Nemeth ZH, Deitch EA, Szabó C. Spermine differentially regulates the production of interleukin-12 p40 and interleukin10 and suppresses the release of the thelper 1 cytokine interferon- $\gamma$. Shock (2000) 14:144-9. doi: 10.1097/00024382-200014020-00012

114. Fan GC, Rong XZ, Wang XM, Liu SR, Zhou YP, Li QH. Influence of exogenous putrescine and cadaverine on pro-inflammatory factors in the peripheral blood of rabbits. Chin J Burns. (2012) 28:451-4. doi: 10.3760/cma.j.issn.1009-2587.2012.06.016

115. Liu B, Jiang X, Cai L, Zhao X, Dai Z, Wu G, et al. Putrescine mitigates intestinal atrophy through suppressing inflammatory response in weanling piglets. J Anim Sci Biotechnol. (2019) 10:69. doi: 10.1186/s40104-019-0379-9

116. Round JL, Lee SM, Li J, Tran G, Jabri B, Chatila TA, et al. The Toll-like receptor pathway establishes commensal gut colonization. Science. (2011) 332:974-7. doi: 10.1126/science.1206095

117. Mazmanian SK, Round JL, Kasper DL. A microbial symbiosis factor prevents intestinal inflammatory disease. Nature. (2008) 453:620-5. doi: 10.1038/nature07008

118. Mazmanian SK, Cui HL, Tzianabos AO, Kasper DL. An immunomodulatory molecule of symbiotic bacteria directs maturation of the host immune system. Cell. (2005) 122:107-18. doi: 10.1016/j.cell.2005.05.007

119. Platt AM, Mowat AMI. Mucosal macrophages and the regulation of immune responses in the intestine. Immunol Lett. (2008) 119:2231. doi: 10.1016/j.imlet.2008.05.009

120. Lee SH, Starkey PM, Gordon S. Quantitative analysis of total macrophage content in adult mouse tissues: imrnunochemical studies with monoclonal antibody f4/80. J Exp Med. (1985) 161:475-89. doi: 10.1084/jem.161.3.475

121. Li JJ, Fang $\mathrm{CH}$, Hui RT. Is hypertension an inflammatory disease? Med Hypotheses. (2005) 64:236-40. doi: 10.1016/j.mehy.2004.06.017

122. Solak Y, Afsar B, Vaziri ND, Aslan G, Yalcin CE, Covic A, et al. Hypertension as an autoimmune and inflammatory disease. Hypertens Res. (2016) 39:56773. doi: $10.1038 / \mathrm{hr} .2016 .35$

123. Dinh QN, Drummond GR, Sobey CG, Chrissobolis S. Roles of inflammation, oxidative stress, and vascular dysfunction in hypertension. Biomed Res Int. (2014) 2014:406960 doi: 10.1155/2014/406960

124. Ji Q, Cheng G, Ma N, Huang Y, Lin Y, Zhou Q, et al. Circulating Th1, Th2, and Th17 levels in hypertensive patients. Dis Markers. (2017) 2017:7146290. doi: 10.1155/2017/7146290

125. Norlander AE, Saleh MA, Kamat NV, Ko B, Gnecco J, Zhu L, et al. Interleukin-17A regulates renal sodium transporters and renal injury in angiotensin II-induced hypertension. Hypertension. (2016) 68:16774. doi: 10.1161/HYPERTENSIONAHA.116.07493

126. Guyenet PG. Sodium is detected by the OVLT to regulate sympathetic tone. Neuron. (2019) 101:3-5. doi: 10.1016/j.neuron.2018.12.015

127. Collister JP, Nahey DB, Hartson R, Wiedmeyer CE, Banek CT, Osborn JW. Lesion of the OVLT markedly attenuates chronic DOCA-salt hypertension in rats. Am J Physiol Regul Integr Comp Physiol. (2018) 315:R568R75. doi: 10.1152/ajpregu.00433.2017

128. Lee CL, Wang CM, Kuo YH, Yen HR, Song YC, Chou YL, et al. IL17A inhibitions of indole alkaloids from traditional Chinese medicine Qing Dai. J Ethnopharmacol. (2020) 255:112772. doi: 10.1016/j.jep.2020. 112772

129. Berg DJ, Davidson N, Kühn R, Müller W, Menon S, Holland G, et al. Enterocolitis and colon cancer in interleukin-10-deficient mice are associated with aberrant cytokine production and CD4+ Th1-like responses. J Clin Invest. (1996) 98:1010-20. doi: 10.1172/JCI118861

130. Ziello JE, Jovin IS, Huang Y. Hypoxia-Inducible Factor (HIF)-1 regulatory pathway and its potential for therapeutic intervention in malignancy and ischemia. Yale J Biol Med. (2007) 80:51-60.

131. Huang Y, Di Lorenzo A, Jiang W, Cantalupo A, Sessa WC, Giordano FJ. Hypoxia-inducible factor- $1 \alpha$ in vascular smooth muscle regulates blood pressure homeostasis through a peroxisome proliferator-activated receptor- $\gamma$-angiotensin II receptor type 1 axis. Hypertension. (2013) 62:63440. doi: 10.1161/HYPERTENSIONAHA.111.00160

132. Sun L, Li T, Tang H, Yu K, Ma Y, Yu M, et al. Intestinal epithelial cellsderived hypoxia-inducible factor- $1 \alpha$ is essential for the homeostasis 
of intestinal intraepithelial lymphocytes. Front Immunol. 10:806. doi: 10.3389/fimmu.2019.00806

133. Yoneno K, Hisamatsu T, Shimamura K, Kamada N, Ichikawa R, Kitazume MT, et al. TGR5 signalling inhibits the production of pro-inflammatory cytokines by in vitro differentiated inflammatory and intestinal macrophages in Crohn's disease. Immunology. (2013) 139:19-29. doi: 10.1111/imm.12045

134. Ramakrishna C, Kujawski M, Chu H, Li L, Mazmanian SK, Cantin EM. Bacteroides fragilis polysaccharide A induces IL-10 secreting B and $\mathrm{T}$ cells that prevent viral encephalitis. Nat Commun. (2019) 10:113. doi: 10.1038/s41467-019-09884-6

Conflict of Interest: The author declares that the research was conducted in the absence of any commercial or financial relationships that could be construed as a potential conflict of interest.
Publisher's Note: All claims expressed in this article are solely those of the authors and do not necessarily represent those of their affiliated organizations, or those of the publisher, the editors and the reviewers. Any product that may be evaluated in this article, or claim that may be made by its manufacturer, is not guaranteed or endorsed by the publisher.

Copyright $\odot 2021$ Cookson. This is an open-access article distributed under the terms of the Creative Commons Attribution License (CC BY). The use, distribution or reproduction in other forums is permitted, provided the original author(s) and the copyright owner(s) are credited and that the original publication in this journal is cited, in accordance with accepted academic practice. No use, distribution or reproduction is permitted which does not comply with these terms. 